\title{
Comparative Organics Remediation Properties of Nanostructured Graphene Doped Titanium Oxide and Graphene Doped Zinc Oxide Photocatalysts
}

\author{
Srikanth Gunti' ${ }^{1}$ Ashok Kumar' ${ }^{1}$ Manoj K. Ram ${ }^{2}$ \\ ${ }^{1}$ Department of Mechanical Engg, University of South Florida, Tampa, USA \\ ${ }^{2}$ NREC/CERC, University of South Florida, Tampa, USA \\ Email: ${ }^{*}$ mkram@usf.edu
}

Received 6 May 2015; accepted 27 July 2015; published 30 July 2015

Copyright $@ 2015$ by authors and Scientific Research Publishing Inc.

This work is licensed under the Creative Commons Attribution International License (CC BY).

http://creativecommons.org/licenses/by/4.0/C) (i) 0 (c) Access

\begin{abstract}
In recent years, we have accomplished effective organics remediation using titanium oxide $\left(\mathrm{TiO}_{2}\right)$ doped transition metals, zinc oxide (ZnO) nanowires and silver \& palladium doped $\mathrm{ZnO}$ nanowires. The present manuscript displays the advantage of organic remediation in both $\mathrm{UV}$ and visible radiation using graphene (G) doped $\mathrm{TiO}_{2}$ nanoparticles, $\mathrm{G}$ doped $\mathrm{ZnO}$ nanowires. The nanostructured $\mathrm{G}_{-} \mathrm{TiO}_{2}$ nanoparticles and $\mathrm{G}-\mathrm{ZnO}$ nanowires were synthesized using sol-gel and hydrothermal methods. The nanostructured materials were characterized using scanning electron microscopy (SEM) and X-Ray diffraction (XRD), procedures. The remediation of organic compounds (naphthalene, methyl orange) in water was achieved under both UV and visible radiation using graphene doped nanostructured photocatalytic materials. The advantage of graphene doped ZnO nanowires as well as $\mathrm{G}_{-} \mathrm{TiO}_{2}$ nanoparticles has revealed organics remediation in both $\mathrm{UV}$ and visible radiation of light.
\end{abstract}

Keywords

Nanostructures, Organic Compounds, Sol-Gel Growth, Visible and Ultraviolet Spectrometers, Oxides

\section{Introduction}

The organic decontamination in water is generally achieved by combination of chemical, physical [1]-[6] and biological techniques [7]-[12]. The organic such as petroleum oil (combination of volatile organic, naphthalene,

\footnotetext{
${ }^{*}$ Corresponding author.

How to cite this paper: Gunti, S., Kumar, A. and Ram, M.K. (2015) Comparative Organics Remediation Properties of Nanostructured Graphene Doped Titanium Oxide and Graphene Doped Zinc Oxide Photocatalysts. American Journal of Analytical Chemistry, 6, 708-717. http://dx.doi.org/10.4236/ajac.2015.68068
} 
toluene, type A oil, etc.) is remediated from water using various surfactants, sorbent, flocculants—bioremediation and occasionally in situ burning methods [13]-[16]. Though, each technique has its own benefits and disadvantages, however, the remediation is related to chemical and physical properties of water as well as related remediation technique. The residues of the oil remain in water while remediated using most of the techniques except bioremediation, which has its own numerous drawbacks [17] [18]. Recently, our group has completed extensive remediation of several organic compounds including oil using $\mathrm{TiO}_{2}$ and $\mathrm{ZnO}$ based nanostructured materials in immobilized and colloidal dispersion compounds, where the chemicals were remediated using the UV-vis and visible radiation of light [19]-[23]. The remediation is certainly dependent on the formation of free radical ( $\mathrm{OH}$ and $\mathrm{O}_{2}^{-}$), nature of the nanostructured based materials $\mathrm{TiO}_{2}$ and/or $\mathrm{ZnO}$ and doping of transition metal [24] [25]. Besides, our group has effectively remediated number of chemicals (toluene, methylene orange (MO), naphthalene etc.), using photocatalyst nanocomposite materials in visible radiation of light [19]-[21].

The use of transition metal as well as non-metal dopants in $\mathrm{TiO}_{2}$ photocatalyst is to narrow the bang gap which could increase photocatalytic activity in the visible light [26]-[30]. The sol-gel technique of photocatalyst synthesis allows to control and manage chemicals homogeneously and processed reaction conditions for yielding nanosized metallic oxide photocatalysts [31] [32]. The graphene doped $\mathrm{TiO}_{2}$ has revealed remediation of organics in the visible light. Yang Yang et al. have shown remediation of $\mathrm{ZnO}$ nanowires where iron doping was prepared on the seeding layer [20]-[22]. Further, Udom et al. have used silver dopant in seeding layer to manufacture $\mathrm{ZnO}$ nanowires for remediation of several organic compounds [21]. Yang Yang et al. doped the $\mathrm{ZnO}$ seeding layer before the growth of $\mathrm{ZnO}$ nanowires [21] [23].

The present paper is devoted to understanding qualitatively and quantitatively the remediation properties by graphene- $\mathrm{ZnO}$ nanowires, graphene- $\mathrm{TiO}_{2}$ nanocomposite, and comparing the outcomes with graphene- $\mathrm{TiO}_{2}$ nanoparticles and commercial photocatalyst $\mathrm{TiO}_{2}$ and $\mathrm{ZnO}$ nanoparticles. The nanowires were synthesized using the graphene with seeding photocatalytic nanomaterials (different sizes) in zinc nitrate and hexamine. The graphene- $\mathrm{ZnO}$ nanowires, graphene- $\mathrm{TiO}_{2}$ nanocomposite, and compared the outcomes with graphene- $\mathrm{TiO}_{2}$ nanoparticles nanostructured materials were characterized using X-ray diffraction, scanning electron microscopy (SEM) techniques. The doping of graphene onto $\mathrm{TiO}_{2}$ in both nanoparticles and nanowire structure is studied due to unique properties of graphene. The remediation of $\mathrm{MO}$ and naphthalene in water was studied quantitatively and qualitatively. In our experimental set up, initiatives have been taken to pass radiation on light on a reaction chamber from both top to bottom ends, separately, and remediation has been studied as a function of time (hours). The remediation experiments were completed using both nanostructured materials in immobilized substrates (example: petri discs) as well as in nanoparticles in colloidal form. The colloidal/suspension particles after remediation were removed using centrifuge, and the filtered water was tested using UV-vis measurements. In design of our experiments, the factors have been considered in estimating the influence of individual variable and their interaction to organize maximum number of experiments.

The MO remediation is shown in Figure 1 using $\mathrm{G}-\mathrm{TiO}_{2}$ nanostructured material. The schematic has revealed how $\mathrm{G}_{-} \mathrm{TiO}_{2}$ produces radical with the use of water molecule and oxygen. The free radicals $\mathrm{OH}$ and $\mathrm{O}_{2}^{-}$were created when light interacted with $\mathrm{G}-\mathrm{TiO}_{2}$ nanostructured materials. The pollutants were oxidized and finally broke into carbon dioxide $\left(\mathrm{CO}_{2}\right)$ and $\mathrm{H}_{2} \mathrm{O}$ molecules. The stepwise remediation of pollutant is given in Equation (1)-(7). Further, Figure 1 shows schematic of reaction of $\mathrm{G}-\mathrm{TiO}_{2}$ for remediation of MO.

$$
\begin{aligned}
& \mathrm{G}^{-\mathrm{TiO}_{2}}+h v \rightarrow \mathrm{G}^{-\mathrm{TiO}_{2}}\left(\mathrm{e}^{-}+\mathrm{h}^{+}\right) \\
& \mathrm{H}_{2} \mathrm{O} \rightarrow \mathrm{H}^{+}+\mathrm{OH}^{-} \\
& \mathrm{G}\left(\mathrm{e}^{-}\right) / \mathrm{TiO}_{2}\left(\mathrm{~h}^{+}\right)+\mathrm{O}_{2} \rightarrow \mathrm{G}-\mathrm{TiO}_{2}\left(\mathrm{~h}^{+}\right)+\mathrm{O}_{2}^{-} \\
& \mathrm{G}\left(\mathrm{e}^{-}\right)-\mathrm{TiO}_{2}\left(\mathrm{~h}^{+}\right)+\mathrm{OH}^{-} \rightarrow \mathrm{G}\left(\mathrm{e}^{-}\right)-\mathrm{TiO}_{2}+\mathrm{OH} \\
& \mathrm{G}\left(\mathrm{e}^{-}\right)-\mathrm{TiO}_{2}\left(\mathrm{~h}^{+}\right)+\mathrm{OH}+\mathrm{R}(\text { pollutant }) \rightarrow \mathrm{G}\left(\mathrm{e}^{-}\right)-\mathrm{TiO}_{2}\left(\mathrm{~h}^{+}\right)+\mathrm{OH}^{-}+\mathrm{R}^{*}(\text { oxidized }) \\
& \mathrm{G}\left(\mathrm{e}^{-}\right)-\mathrm{TiO}_{2}\left(\mathrm{~h}^{+}\right)+\mathrm{O}_{2}^{-}+\mathrm{R} \rightarrow \mathrm{G}\left(\mathrm{e}^{-}\right) / \mathrm{TiO}_{2}\left(\mathrm{~h}^{+}\right)+\mathrm{O}_{2}+\mathrm{R}^{* *} \text { (reduced) } \\
& \left.\mathrm{R}^{*}(\text { oxidized }) \text { or } \mathrm{R}^{* *} \text { (reduced }\right) \rightarrow(\text { final products }) \rightarrow \mathrm{CO}_{2}+\mathrm{H}_{2} \mathrm{O}
\end{aligned}
$$




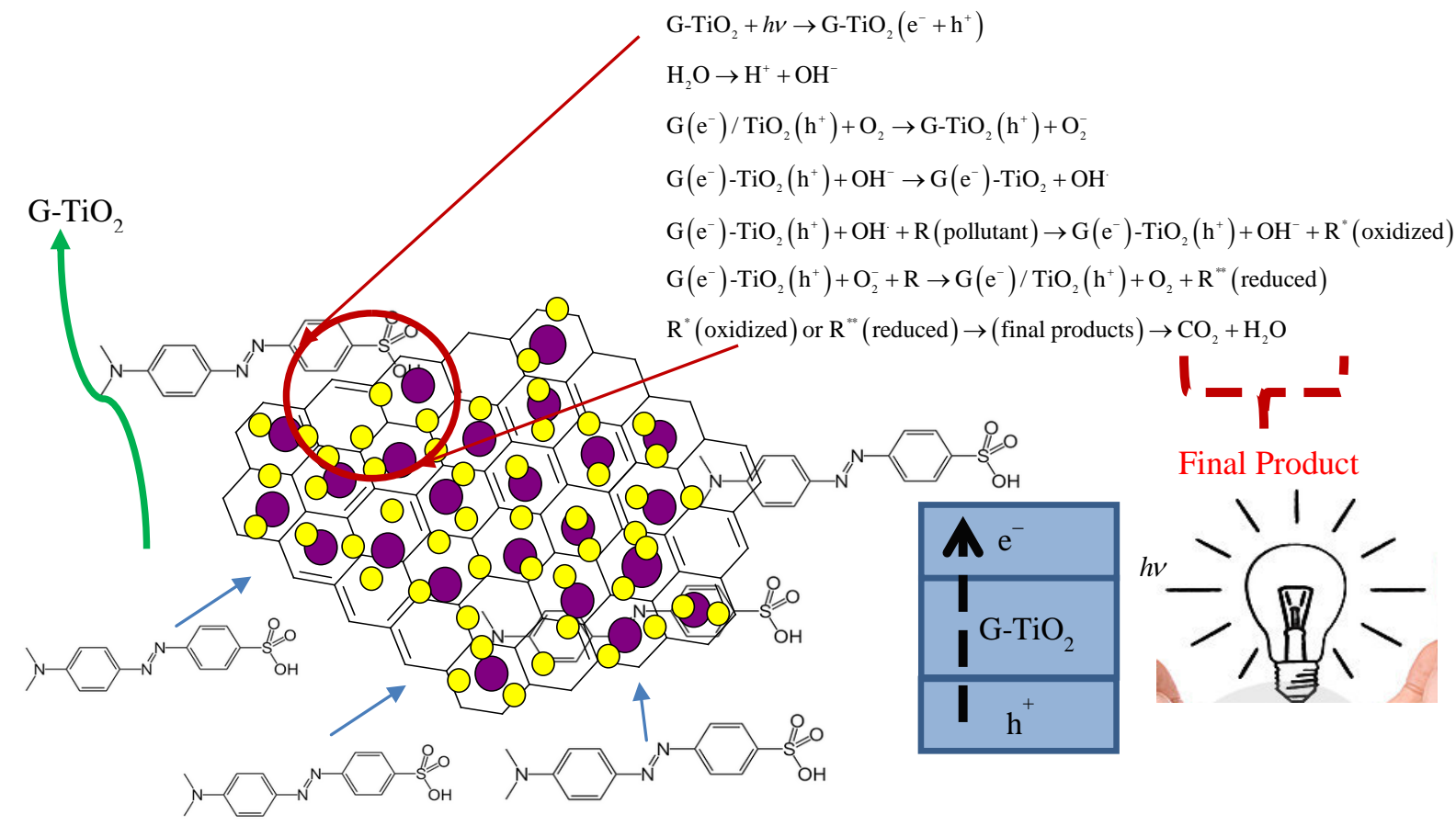

Figure 1. Schematic of remediation of methyl orange using $\mathrm{G}-\mathrm{TiO}_{2}$ nanoparticles.

\section{Experiment}

\subsection{Materials}

The chemicals such as hydrochloric acid ( $\mathrm{HCl}$ ), propanol, titanium (IV) isopropoxide, sodium hydroxide ( $\mathrm{NaOH})$, zinc oxide $(\mathrm{ZnO})$ particles, zinc nitrate hexahydrate $\left(\mathrm{Zn}\left(\mathrm{NO}_{3}\right)_{2} \cdot 6 \mathrm{H}_{2} \mathrm{O}\right)$, hexamethylenetetramine (HMTA), methyl orange, naphthalene and other reagents were used for the preparation of nanostructured materials and the chemicals were procured from Sigma-Aldrich (USA). The commercial $\mathrm{TiO}_{2} \mathrm{P} 25$ was also obtained for comparative remediation studies. The graphene platelets of size $<20 \mathrm{~nm}$ in thickness were acquired from Angstrom Materials, a commercial company in USA.

\subsection{Synthesis of $\mathrm{G}^{-} \mathrm{TiO}_{2}$ Nanoparticles and Nanocomposite}

The G- $\mathrm{TiO}_{2}$ nanoparticles were synthesized using mixture of titanium (IV) isopropoxide in propanol solution. Initially, $0.193 \mathrm{gm}$ of graphene $(\mathrm{G})$ was mixed in $20 \mathrm{ml}$ propanol with 30 minutes of sonication with slowly addition of $4 \mathrm{ml}$ of titanium (IV) isopropoxide in round bottom flask. The mixture was stirred for 30 minutes, and later, $\mathrm{HCl}$ solution was added drop wise, and the solution to stir for another 24 hours at room temperature. The precipitate was washed using deionized water for removing the unreacted organic residues, later it was centrifuged and dried at $100^{\circ} \mathrm{C}$.

The nanocomposite $\mathrm{G}-\mathrm{TiO}_{2}$ was synthesized by using titanium oxide $\left(\mathrm{TiO}_{2}\right)$ nanoparticles in sodium hydroxide $(\mathrm{NaOH})$. The synthesis was initiated by addition of $6 \mathrm{gm} \mathrm{TiO}_{2}(\mathrm{P} 25)$ and $0.2 \mathrm{gm}$ of graphene (G) with addition of $70 \mathrm{ml}$ of $10 \mathrm{M} \mathrm{NaOH}$ solution. The resulting solution was stirred for 30 minutes and, it was kept at a constant temperature of $150^{\circ} \mathrm{C}$ for $48 \mathrm{hrs}$. The precipitate was washed using $0.1 \mathrm{M} \mathrm{HCl}$ solution for several times with an observation that the precipitate showed $\mathrm{pH}$ below 7 . The precipitate was centrifuged, and dried at $100^{\circ} \mathrm{C}$ for 24 hrs. The $\mathrm{G}-\mathrm{TiO}_{2}$ nanocomposite was heated at $350^{\circ} \mathrm{C}$ for $4 \mathrm{hrs}$.

\subsection{Synthesis of G-ZnO Nanowires}

The graphene (G) -zinc oxide (G-ZnO) was synthesized by using $\mathrm{Zn}\left(\mathrm{NO}_{3}\right)_{2} \cdot 6 \mathrm{H}_{2} \mathrm{O}$, hexamethylenetetramine HMTA and $\mathrm{G}$. Initially $25 \mathrm{mM} / \mathrm{l}$ of $\mathrm{Zn}\left(\mathrm{NO}_{3}\right)_{2} \cdot 6 \mathrm{H}_{2} \mathrm{O}$ and HMTA solutions were mixed in deionized water (DI) and 0.1 gm of $\mathrm{G}$ was added to the solution, and maintained at $80^{\circ} \mathrm{C}$. Zinc oxide $(\mathrm{ZnO})$ nanoparticles with normal size 
(avg $100 \mathrm{~nm}$ ) were sonicated in $1 \mathrm{ml}$ of DI water with addition of solution as nucleation sites for the growth of nanowires. The solution was kept at $80^{\circ} \mathrm{C}$ for 4 hours, and washed with DI water \& ethanol and centrifuged. The samples were dried at $100^{\circ} \mathrm{C}$ for $24 \mathrm{hrs}$.

\subsection{Experiment Setup}

The photocatalytic activity of materials $\mathrm{G}-\mathrm{TiO}_{2}$ nanoparticles (synthesized by sol-gel), G- $\mathrm{TiO}_{2}$ nanocomposite (synthesized by hydrothermal), and G-ZnO nanowire (synthesized by hydrothermal) and commercially available P25 were studied to remediate MO as an indicator. In the process, $0.2 \mathrm{gm}$ of photocatalytic material were coated onto a petri dish with the use of acetic acid \& dried at room temperature. Later, it was heated at $200^{\circ} \mathrm{C}$ for 30 minutes. $20 \mathrm{ppm}$ of $40 \mathrm{ml} \mathrm{MO}$ was added inside the coated petri dishes, and illuminated by light of 30-watt with light intensity of $800 \mathrm{~W} / \mathrm{m}^{2}$. The remediated samples were collected from the main remediating samples in an interval of an hour. Attempts were also taken to vary the time interval in some cases in collecting the remediating sample. JASCO V-530 UV-Visible Spectrometer was used to measure the absorbance of MO. Initial concentration was taken as $C_{o}$ at 0 hours. The percentage of concentration ratio was calculated by using $C_{n} / C_{o}$ with respect to time in hours.

Based on the procedure for $\mathrm{MO}$, the performance of $\mathrm{G}-\mathrm{TiO}_{2}$ nanoparticle, $\mathrm{G}-\mathrm{TiO}_{2}$ nanocomposite and $\mathrm{G}-\mathrm{ZnO}$ nanowire were used on naphthalene in water. $30 \mathrm{ppm}$ of naphthalene was used as contaminant in $100 \mathrm{ml}$ of deionised water. $20 \mathrm{mg}$ of sodium dodecyl-sulfonate surfactant was used to enhance the contact of photocatalyst and pollutants.The light intensity of $800 \mathrm{~W} / \mathrm{m}^{2}$ generated by 30 watt bulb was used to remediate naphthalene from water. The samples were analyzed using UV-vis spectrum for naphthalene presence in remediated water at 0 and 48 hrs similar to one discussed for MO. The naphthalene has UV-vis absorption at $221 \mathrm{~nm}, 286 \mathrm{~nm}$ and $312 \mathrm{~nm}$. The values at these peaks were considered to determine the percentage (\%) of naphthalene in the remediated water samples.

\section{Characterization}

\subsection{X-Ray Diffraction}

XRD study of $\mathrm{G}-\mathrm{TiO}_{2}$ nanoparticles is shown below in Figure 2. The diffraction peak at $26.51^{\circ}$ indicates the presence of graphene. The peaks at 24.94, 37.87, 47.88, 54.60, 63.08, 69.26, 74.87, 83.09 degrees indicate the anatase phase of $\mathrm{TiO}_{2}$ in nanocomposite of $\mathrm{G}-\mathrm{TiO}_{2}$.

The XRD study of $\mathrm{G}-\mathrm{TiO}_{2}$ nanocomposite is shown in Figure 3, which observes the presence of graphene at

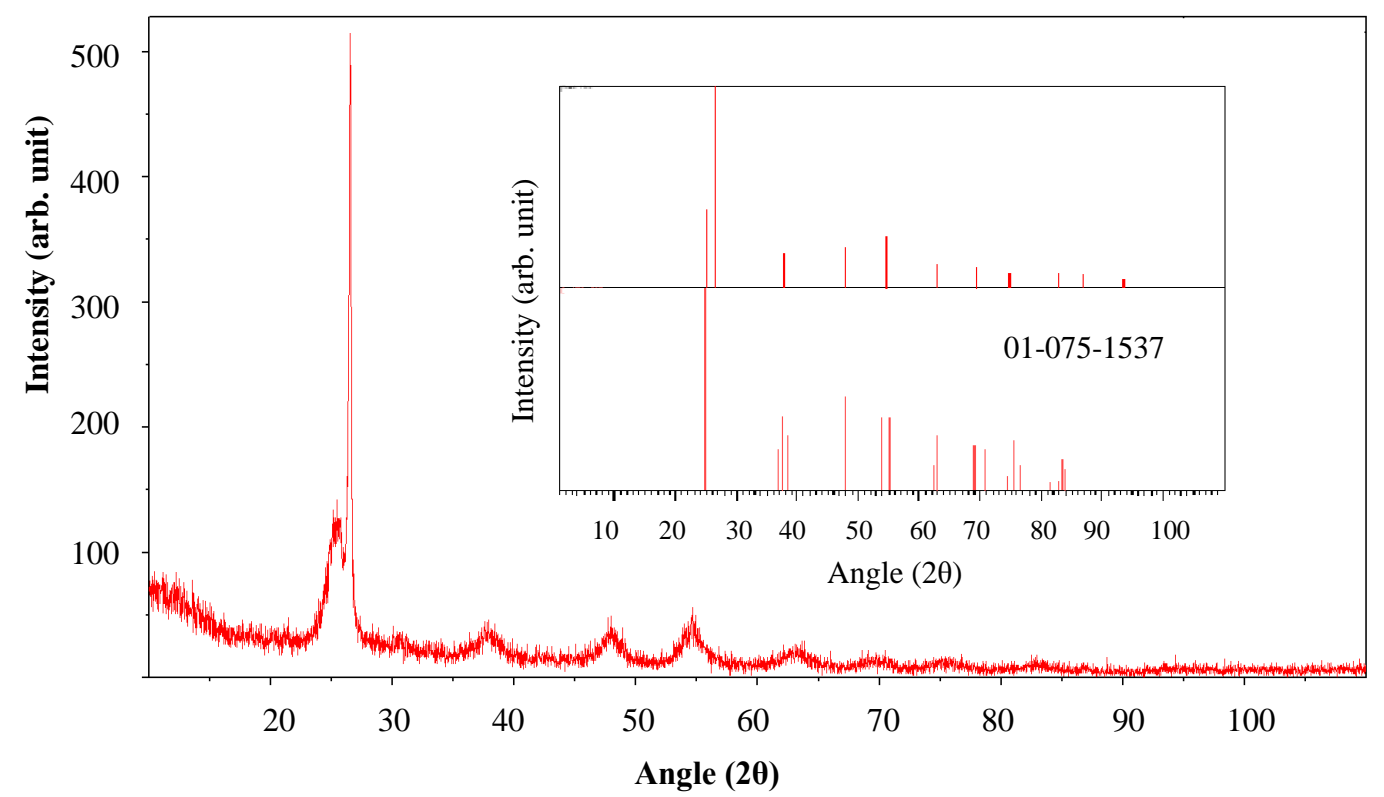

Figure 2. XRD image of $\mathrm{G}-\mathrm{TiO}_{2}$ nanoparticles showing the peaks of graphene and anatase (01-075-1537) phase of $\mathrm{TiO}_{2}$. 
$26.54^{\circ}$ diffraction peak. The diffraction angle $(2 \theta)$ at 25.19 , 38.08, and 48.01 indicate anatase phase (01-0782486) of $\mathrm{TiO}_{2}$ and a $2 \theta$ at 27.40, 36.08, and 54.37 indicates the rutile phase (01-075-1748) of $\mathrm{TiO}_{2}$. Based on the length of the diffraction peak, ratio of rutile to anatase phase has been estimated to be 1.32:1, which indicates the material, has relatively added rutile phase than anatase phase.

The XRD image of G-ZnO nanowires is as shown in Figure 4. The peak at $26.49^{\circ}$ shows the presence of graphene. The peaks in 00-036-1451 in Figure 4, shows the presence of $\mathrm{ZnO}$ structure.

\subsection{Scanning Electron Microscope (SEM)}

The surface morphology of $\mathrm{G}-\mathrm{TiO}_{2}$ nanoparticles is shown in Figures 5(a)-(d). It reveals the compact particles distribution in the $\mathrm{G}_{-} \mathrm{TiO}_{2}$ nanostructured material. A potential explanation for formation for compact particle structure in $\mathrm{G}-\mathrm{TiO}_{2}$ is due to dispersion of $\mathrm{TiO}_{2}$ particles on graphene sheets. Figure 5(d) shows the SEM images of $\mathrm{G}-\mathrm{TiO}_{2}$ nanoparticle at $500 \mathrm{~nm}$ unit magnification. The typical graphene structure is covered by the $\mathrm{TiO}_{2}$

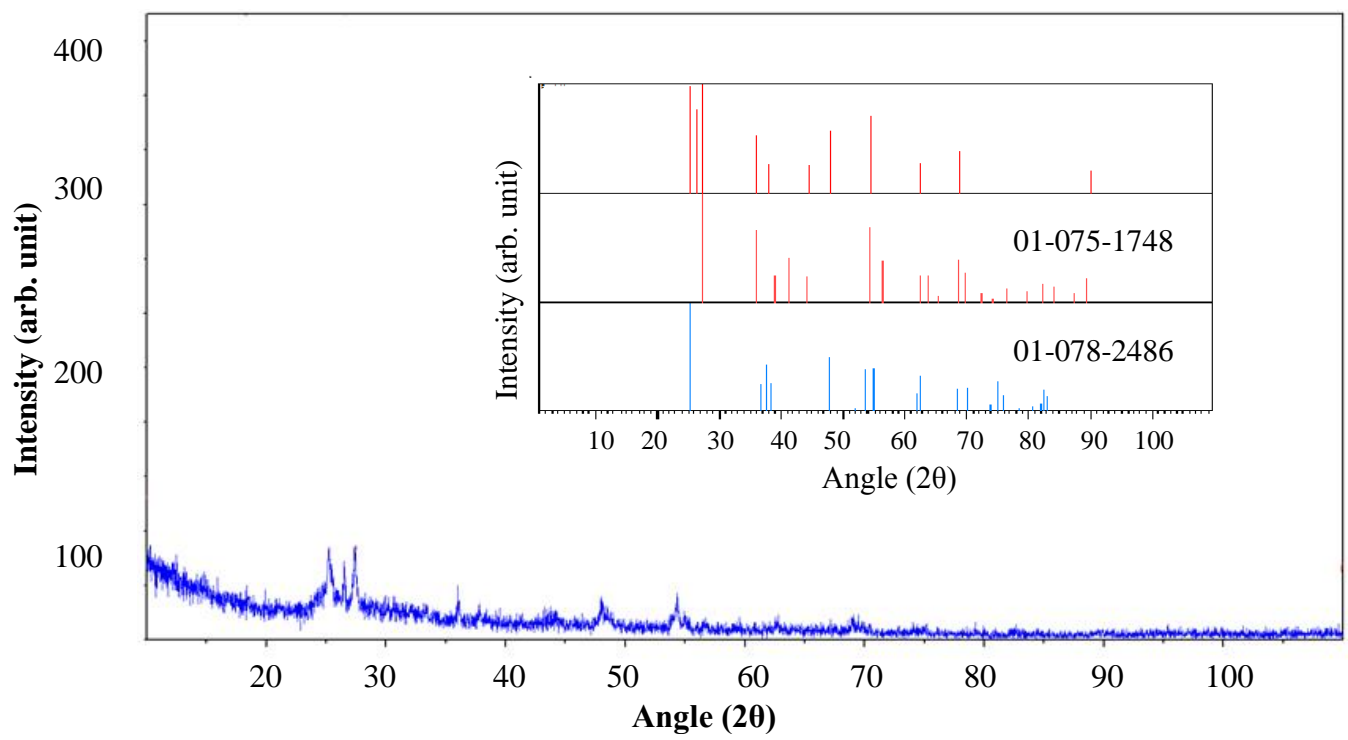

Figure 3. XRD image of $\mathrm{G}-\mathrm{TiO}_{2}$ nanocomposite showing the peaks of graphene and anatase (01-0782486) and rutile (01-075-1748) phase of $\mathrm{TiO}_{2}$.

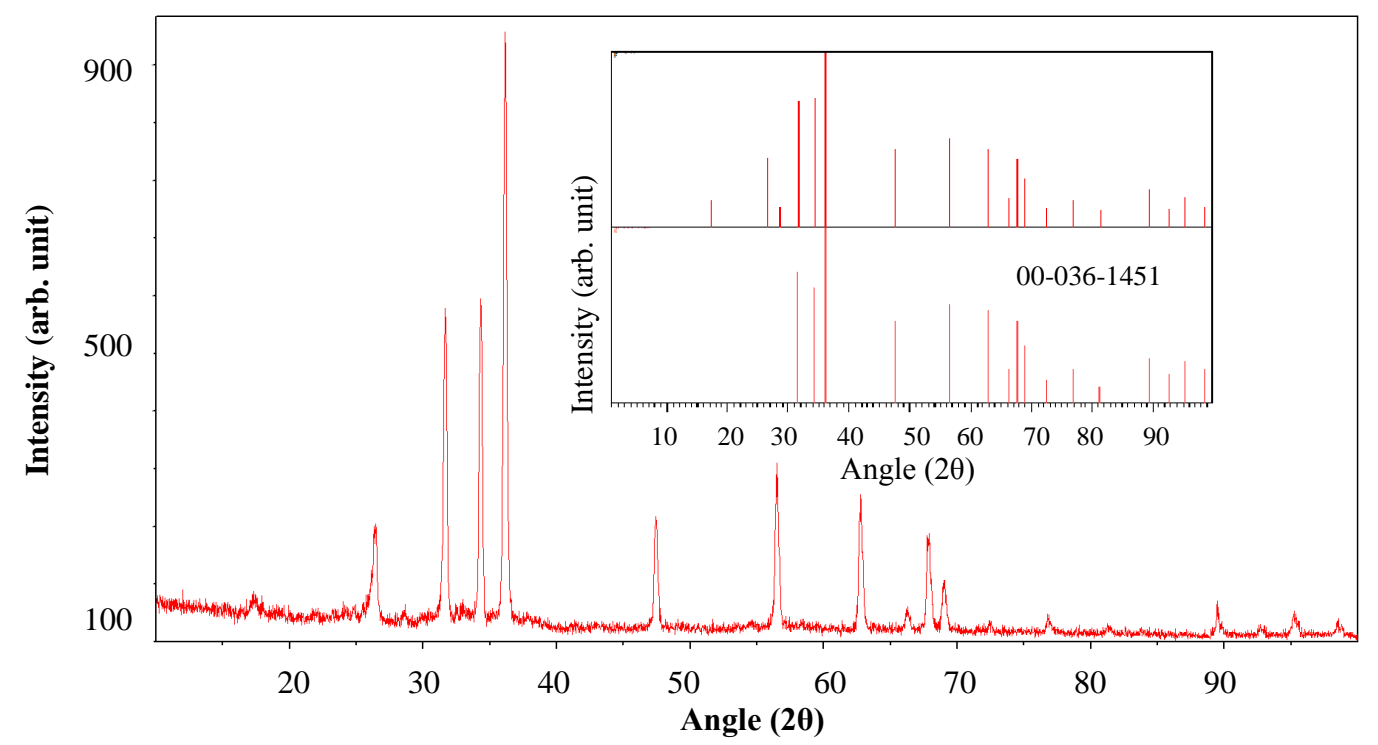

Figure 4. XRD image of G-ZnO nanowire showing the peaks of graphene and (00-036-1451) ZnO. 
nanoparticle.

We made an attempt to synthesize nanowires for keeping the $\mathrm{G}-\mathrm{TiO}_{2}$ seeding layer. However, the G-TiO nanocomposite wires were not formed under similar growth condition as indicated by SEM images in Figure 6. However, the $\mathrm{G}-\mathrm{TiO}_{2}$ nanostructured has been found similar to one studied in Figure 5.

Figure 7 observes the nanowires structure of G-ZnO. The $\mathrm{ZnO}$ nanowires have been found to form on graphene sheets. The sizes of $\mathrm{ZnO}$ nanowires coated with graphene were controlled by the size of seeding layer of $\mathrm{ZnO}$. The size of G-ZnO nanowires have been found to be between 200 - $400 \mathrm{~nm}$ as shown in Figure 7.

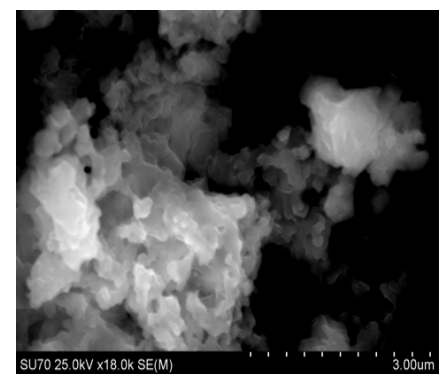

(a)

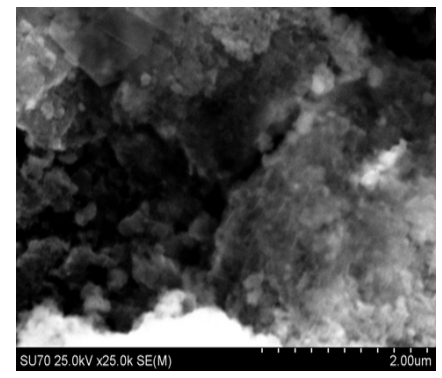

(c)

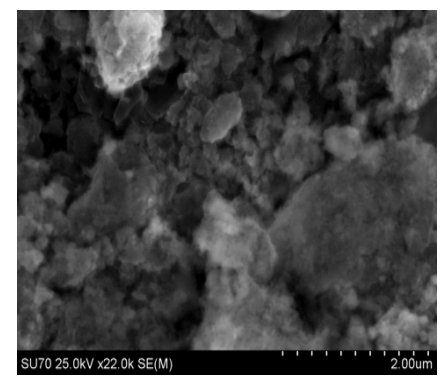

(b)

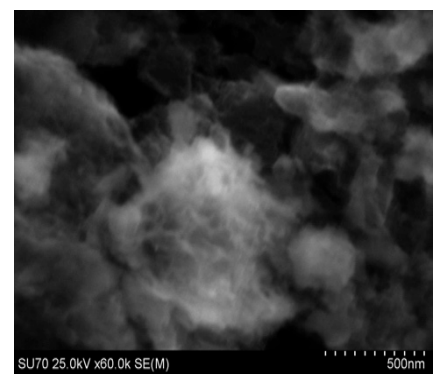

(d)

Figure 5. SEM images of $\mathrm{G}-\mathrm{TiO}_{2}$ nanoparticle at different magnification (a)-(d).

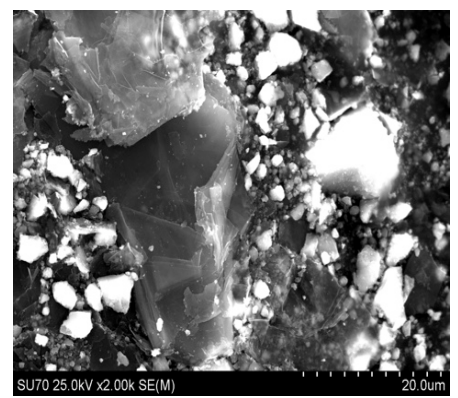

(a)

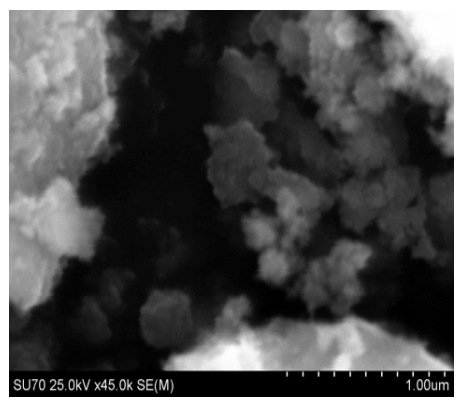

(c)

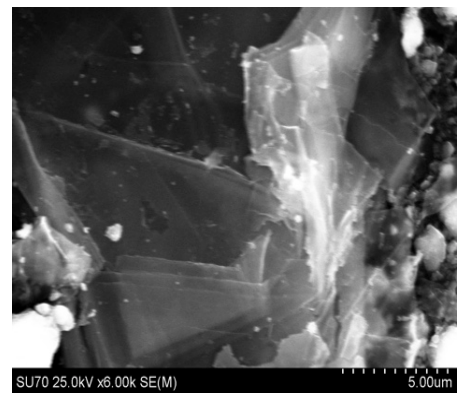

(b)

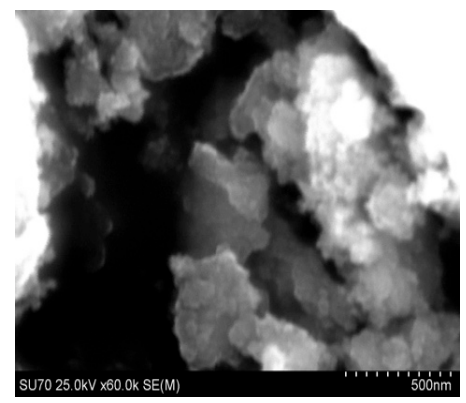

(d)

Figure 6. SEM images $\mathrm{G}_{-} \mathrm{TiO}_{2}$ nanocomposite at different magnification (a)-(d). 


\section{Results and Discussion}

Figure 8 reveals the degradation of $\mathrm{MO}$ using $\mathrm{G}-\mathrm{TiO}_{2}$ nanoparticles, $\mathrm{G}-\mathrm{TiO}_{2}$ nanocomposite, $\mathrm{G}-\mathrm{ZnO}$ nanowire and commercially available $\mathrm{P} 25$. G- $\mathrm{TiO}_{2}$ nanoparticle observes the improved photocatalytic performance by removing entirely the MO from water solution in less than 5 hours.

Figures 9(a)-(c) show disappearance of UV-vis absorption peaks at 221, 286 and $321 \mathrm{~nm}$ from remediated samples. The $\mathrm{G}-\mathrm{TiO}_{2}$ nanoparticles have been found to perform better than the $\mathrm{G}-\mathrm{TiO}_{2}$ nanocomposite, and $\mathrm{G}-\mathrm{ZnO}$ nanowires for the decontamination of naphthalene. Based on the experimental investigation, the $\mathrm{MO}$ remediation in water using $\mathrm{G}-\mathrm{TiO}_{2}$ photocatalytic materials (Figure 9) has been plotted for comparative \% $\mathrm{C}_{\mathrm{n}}$ / $\mathrm{C}_{\mathrm{o}}$ vs time duration (hrs) plots. The similar plots can also be shown with the change of $\mathrm{TiO}_{2}$ nanopartciles to $\mathrm{ZnO}$ nanowires using graphene matrix.

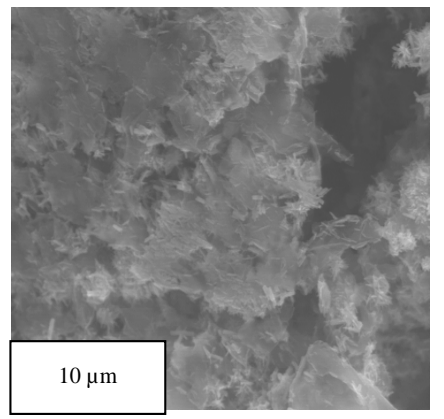

(a)

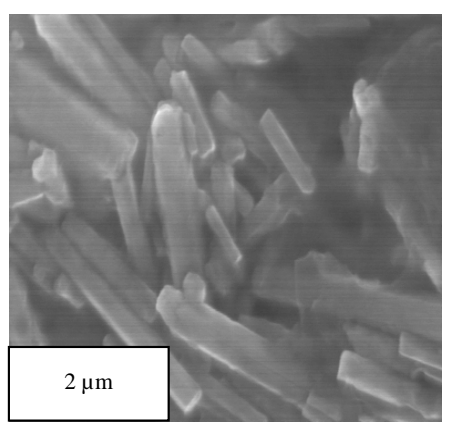

(c)

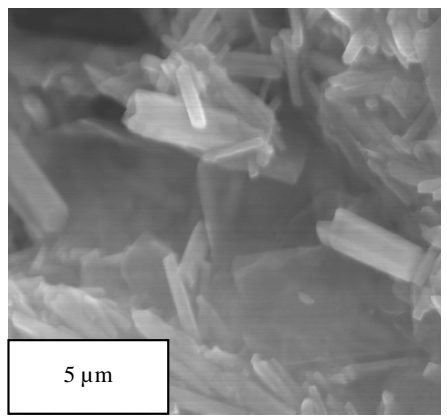

(b)

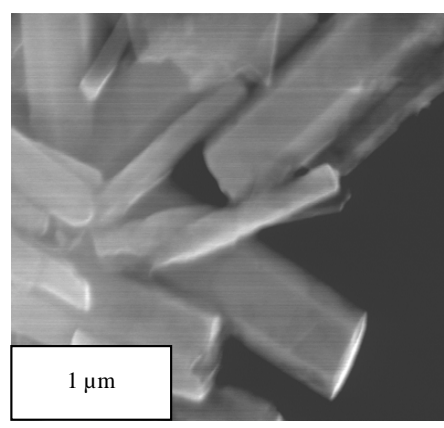

(d)

Figure 7. SEM images of G-ZnO at different magnifications (a)-(d).

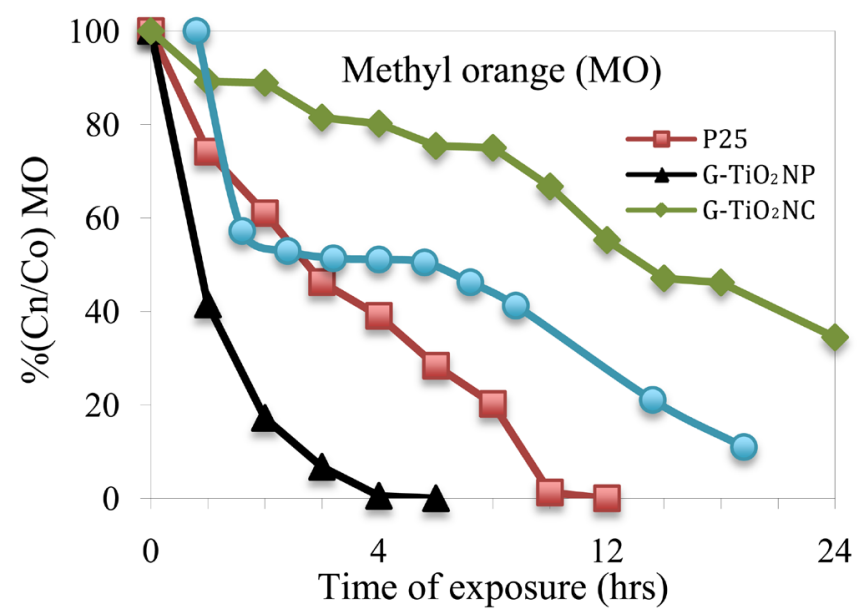

Figure 8.Comparative graph of \% $\mathrm{Cn} / \mathrm{Co}$ vs time of exposure (hrs) for $\mathrm{G}-\mathrm{TiO}_{2}$ nanoparticles, $\mathrm{G}-\mathrm{TiO}_{2}$ nanocomposite, G-ZnO nanowire and commercially available P25 for methyl orange (MO). 


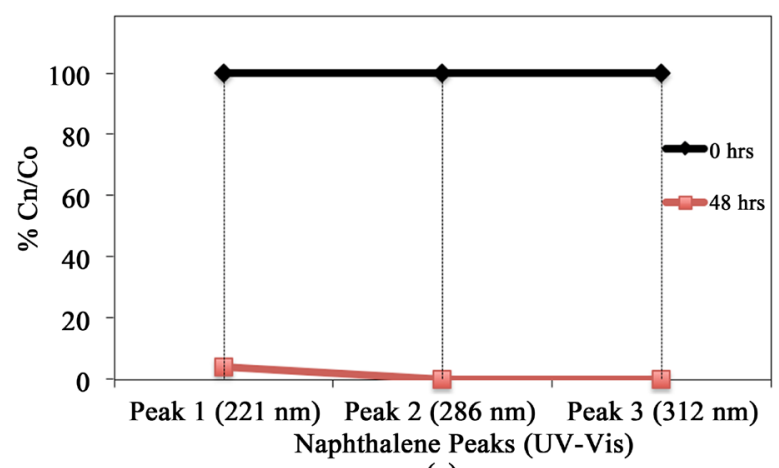

(a)

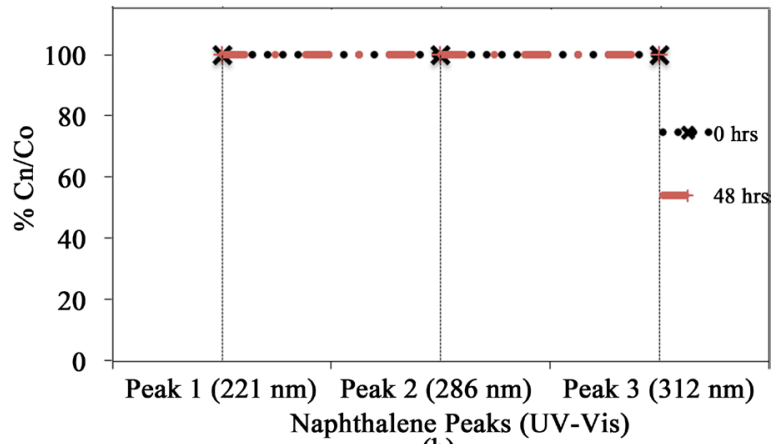

(b)

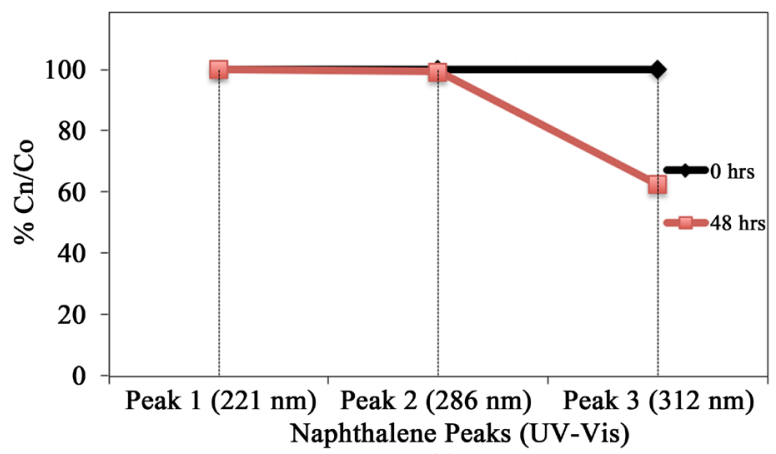

(c)

Figure 9. Comparative graph of $\% \mathrm{Cn} / \mathrm{Co}$ vs time duration (hrs) for $\mathrm{G}-\mathrm{TiO}_{2}$ nanoparticles, $\mathrm{G}-\mathrm{TiO}_{2}$ nanocomposite, G-ZnO nanowire for naphthalene respectively. (a) $\mathrm{G}-\mathrm{TiO}_{2} \mathrm{NP}$; (b) $\mathrm{G}_{-} \mathrm{TiO}_{2} \mathrm{NC}$; (c) G-ZnO NW.

\section{Conclusion}

Sol gel G- $\mathrm{TiO}_{2}$ nanoparticles have superior photocatalytic properties than $\mathrm{G}-\mathrm{TiO}_{2}$ nanocomposite (synthesized by hydrothermal), G-ZnO nanowires (synthesized by hydrothermal) and commercially available P25 under visible light. The photocatalytic remediation of both of $\mathrm{MO}$ and naphthalene has been faster using $\mathrm{G}^{-\mathrm{TiO}_{2}}$ nanocomposite than other synthesized nanomaterials under identical condition. The sol-gel $\mathrm{G}-\mathrm{TiO}_{2}$ nanoparticles could find applications for cleaning drinking water.

\section{Acknowledgements}

National Science Foundation (NSF) with the grant number 1066649 is greatly acknowledged for financial support. One of the authors, Gunti would like to thank Saumya Sharma and Michael McCrory for SEM and XRD measurements.

\section{References}

[1] Froehner, S., Martins, R.F., Furukawa, W. and Errera, M.R. (2009) Water Remediation by Adsorption of Phenol onto 
Hydrophobic Modified Clay. Water, Air, and Soil Pollution, 199, 107-113. http://dx.doi.org/10.1007/s11270-008-9863-0

[2] Gupta, G., Prasad, G. and Singh, V. (1990) Removal of Chrome Dye from Aqueous Solutions by Mixed Adsorbents: Fly Ash and Coal. Water Research, 24, 45-50. http://dx.doi.org/10.1016/0043-1354(90)90063-C

[3] Mondal, P., Majumder, C. and Mohanty, B. (2006) Laboratory Based Approaches for Arsenic Remediation from Contaminated Water: Recent Developments. Journal of Hazardous Materials, 137, 464-479. http://dx.doi.org/10.1016/j.jhazmat.2006.02.023

[4] Nawar, S.S. and Doma, H.S. (1989) Removal of Dyes from Effluents Using Low-Cost Agricultural By-Products. Science of the Total Environment, 79, 271-279. http://dx.doi.org/10.1016/0048-9697(89)90342-2

[5] Ponder, S.M., Darab, J.G., Bucher, J., Caulder, D., Craig, I., Davis, L., Edelstein, N., Lukens, W., Nitsche, H. and Rao, L. (2001) Surface Chemistry and Electrochemistry of Supported Zerovalent Iron Nanoparticles in the Remediation of Aqueous Metal Contaminants. Chemistry of Materials, 13, 479-486. http://dx.doi.org/10.1021/cm000288r

[6] Poots, V., McKay, G. and Healy, J. (1976) The Removal of Acid Dye from Effluent Using Natural Adsorbents-II Wood. Water Research, 10, 1067-1070. http://dx.doi.org/10.1016/0043-1354(76)90037-3

[7] Megharaj, M., Ramakrishnan, B., Venkateswarlu, K., Sethunathan, N. and Naidu, R. (2011) Bioremediation Approaches for Organic Pollutants: A Critical Perspective. Environment International, 37, 1362-1375. http://dx.doi.org/10.1016/j.envint.2011.06.003

[8] Head, I.M. (1998) Bioremediation: Towards a Credible Technology. Microbiology, 144, 599-608. http://dx.doi.org/10.1099/00221287-144-3-599

[9] Perelo, L.W. (2010) Review: In Situ and Bioremediation of Organic Pollutants in Aquatic Sediments. Journal of Hazardous Materials, 177, 81-89. http://dx.doi.org/10.1016/j.jhazmat.2009.12.090

[10] Mulligan, C., Yong, R. and Gibbs, B. (2001) Remediation Technologies for Metal-Contaminated Soils and Groundwater: An Evaluation. Engineering Geology, 60, 193-207. http://dx.doi.org/10.1016/S0013-7952(00)00101-0

[11] Cunningham, S.D. and Berti, W.R. (1993) Remediation of Contaminated Soils with Green Plants: An Overview. In Vitro Cellular \& Developmental Biology-Plant, 29, 207-212. http://dx.doi.org/10.1007/BF02632036

[12] Oturan, M. (2000) An Ecologically Effective Water Treatment Technique Using Electrochemically Generated Hydroxyl Radicals for in Situ Destruction of Organic Pollutants: Application to Herbicide 2,4-D. Journal of Applied Electrochemistry, 30, 475-482. http://dx.doi.org/10.1023/A:1003994428571

[13] Carmody, O., Frost, R., Xi, Y. and Kokot, S. (2007) Adsorption of Hydrocarbons on Organo-Clays-Implications for Oil Spill Remediation. Journal of Colloid and Interface Science, 305, 17-24. http://dx.doi.org/10.1016/j.jcis.2006.09.032

[14] Pahl, J.W., Mendelssohn, I.A. and Hess, T.J. (1997) The Application of in Situ Burning to a Louisiana Coastal Marsh Following a Hydrocarbon Product Spill: Preliminary Assessment of Site Recovery. International Oil Spill Conference Proceedings, 1997, 823-828. http://dx.doi.org/10.7901/2169-3358-1997-1-823

[15] Schramm, L.L. (2000) Surfactants: Fundamentals and Applications in the Petroleum Industry. Cambridge University Press, Cambridge. http://dx.doi.org/10.1017/CBO9780511524844

[16] Wasay, S., Barrington, S. and Tokunaga, S. (2001) Organic Acids for the in Situ Remediation of Soils Polluted by Heavy Metals: Soil Flushing in Columns. Water, Air, and Soil Pollution, 127, 301-314. http://dx.doi.org/10.1023/A:1005251915165

[17] Boopathy, R. (2000) Factors Limiting Bioremediation Technologies. Bioresource Technology, 74, 63-67. http://dx.doi.org/10.1016/S0960-8524(99)00144-3

[18] Vidali, M. (2001) Bioremediation. An Overview. Pure and Applied Chemistry, 73, 1163-1172. http://dx.doi.org/10.1351/pac200173071163

[19] Alam, T.E., Ram, M.K., Ladanov, M., Alvi, F., Mujumdar, A. and Kumar, A. (2012) Synthesis and Characterization of Novel Graphene Silicon Oxide Nanocomposite Material. MRS Proceedings, Cambridge University Press, Cambridge, mrsf11-1400-s1408-1407. http://journals.cambridge.org/action/displayAbstract?fromPage=online\&aid=8515099\&fileId=S1946427412005003

[20] Udom, I., Ram, M.K., Stefanakos, E.K., Hepp, A.F. and Goswami, D.Y. (2013) One Dimensional-ZnO Nanostructures: Synthesis, Properties and Environmental Applications. Materials Science in Semiconductor Processing, 16, $2070-2083$. http://dx.doi.org/10.1016/j.mssp.2013.06.017

[21] Udom, I., Zhang, Y., Ram, M.K., Stefanakos, E.K., Hepp, A.F., Elzein, R., Schlaf, R. and Goswami, D.Y. (2014) A Simple Photolytic Reactor Employing Ag-doped ZnO Nanowires for Water Purification. Thin Solid Films, 564, 258263. http://dx.doi.org/10.1016/j.tsf.2014.05.057

[22] Ladanov, M., Algarin-Amaris, P., Matthews, G., Ram, M., Thomas, S., Kumar, A. and Wang, J. (2013) Microfluidic 
Hydrothermal Growth of ZnO Nanowires over High Aspect Ratio Microstructures. Nanotechnology, 24, Article ID: 375301. http://dx.doi.org/10.1088/0957-4484/24/37/375301

[23] Zhang, Y., Ram, M.K., Stefanakos, E.K. and Goswami, D.Y. (2013) Enhanced Photocatalytic Activity of Iron Doped Zinc Oxide Nanowires for Water Decontamination. Surface and Coatings Technology, 217, 119-123. http://dx.doi.org/10.1016/j.surfcoat.2012.12.001

[24] Kamat, P.V. (2012) $\mathrm{TiO}_{2}$ Nanostructures: Recent Physical Chemistry Advances. The Journal of Physical Chemistry C, 116, 11849-11851.

[25] Kamat, P.V., Huehn, R. and Nicolaescu, R. (2002) A "Sense and Shoot” Approach for Photocatalytic Degradation of Organic Contaminants in Water. The Journal of Physical Chemistry B, 106, 788-794. http://dx.doi.org/10.1021/jp013602t

[26] Ihara, T., Miyoshi, M., Iriyama, Y., Matsumoto, O. and Sugihara, S. (2003) Visible-Light-Active Titanium Oxide Photocatalyst Realized by an Oxygen-Deficient Structure and by Nitrogen Doping. Applied Catalysis B: Environmental, 42, 403-409. http://dx.doi.org/10.1016/S0926-3373(02)00269-2

[27] Pillai, S.C., Periyat, P., George, R., McCormack, D.E., Seery, M.K., Hayden, H., Colreavy, J., Corr, D. and Hinder, S.J. (2007) Synthesis of High-Temperature Stable Anatase $\mathrm{TiO}_{2}$ Photocatalyst. The Journal of Physical Chemistry C, 111, 1605-1611. http://dx.doi.org/10.1021/jp065933h

[28] Wang, C.-C. and Ying, J.Y. (1999) Sol-Gel Synthesis and Hydrothermal Processing of Anatase and Rutile Titania Nanocrystals. Chemistry of Materials, 11, 3113-3120. http://dx.doi.org/10.1021/cm990180f

[29] Chatterjee, D. and Dasgupta, S. (2005) Visible Light Induced Photocatalytic Degradation of Organic Pollutants. Journal of Photochemistry and Photobiology C: Photochemistry Reviews, 6, 186-205. http://dx.doi.org/10.1016/j.jphotochemrev.2005.09.001

[30] Zhao, G., Kozuka, H. and Yoko, T. (1996) Sol-Gel Preparation and Photoelectrochemical Properties of TiO $\mathrm{Tilms}_{2}$ Containing Au and Ag Metal Particles. Thin Solid Films, 277, 147-154. http://dx.doi.org/10.1016/0040-6090(95)08006-6

[31] Su, C., Hong, B.Y. and Tseng, C.M. (2004) Sol-Gel Preparation and Photocatalysis of Titanium Dioxide. Catalysis Today, 96, 119-126. http://dx.doi.org/10.1016/j.cattod.2004.06.132

[32] Sanchez, C., Lebeau, B., Chaput, F. and Boilot, J.P. (2003) Optical Properties of Functional Hybrid Organic-Inorganic Nanocomposites. Advanced Materials, 15, 1969-1994. http://dx.doi.org/10.1002/adma.200300389 